\title{
A EDUCAÇÃO DO CONTEXTO DA QUESTÃO AGRÁRIA BRASILEIRA E AS POLÍTICAS DO ESTADO PARA A EDUCAÇÃO NO/DO CAMPO
}

\author{
Franciel Coelho Luz de Amorim \\ RaImunda Áurea Dias de Sousa \\ Universidade de Pernambuco (UPE), Petrolina, Pernambuco, Brasil
}

\begin{abstract}
REsUmo: O artigo centra-se nas políticas de educação criada pelo Estado no Brasil, a partir dos interesses da expansão do sistema do capital, especialmente, para o espaço rural que, na contradição, contribui para criação de uma educação que caminha na contramão do sistema - a educação do campo. Esta é construída nas lutas dos movimentos sociais, no momento em que a questão agrária ganha grande evidência justamente pelo escasseamento de alternativas de reinclusão dos expulsos da terra. Nesse sentido, o objetivo do artigo consiste em analisar as políticas do Estado para a educação no/do campo no contexto da questão agrária brasileira. Assim, buscou-se desvelar as políticas educacionais implementadas pelo Estado, em acolhimento às demandas do capital, e a caracterização dos significados do projeto alternativo de educação do campo, emergido nas bases dos movimentos de luta pela terra.
\end{abstract}

PALAVRAS-CHAVE: Questão agrária. Luta pela terra. Políticas educacionais. Educação do campo.

INTRODUÇÃO

Elaboramos, a partir de uma perspectiva histórica, um breve panorama histórico-dialético da educação no contexto da questão agrária 
brasileira, buscando, desde as origens, a natureza e os objetivos da educação rural: ressaltando que dois grandes objetivos permearam as iniciativas de educação oferecida no campo brasileiro. Em um primeiro momento, que vai desde as origens da República até início da década de 1960, os objetivos dessa educação rural eram tão-somente segurar, "fixar" e manter os camponeses no espaço rural, em razão dos efeitos das ondas migratórias campo-cidade.

Em um segundo momento, a partir da década de 1960, os projetos de educação foram sendo elaborados para legitimar as ações da chamada "modernização agrícola", em que a expropriação tomou forma (MARTINS, 2003) para dar lugar aos projetos agrícolas do grande capital. A partir daí, retornam-se aos discursos do campo como local de "atraso", criam-se políticas que forçam os camponeses às cidades, atrelando-se medidas à educação e ao processo educativo de maneira geral, a partir da teoria de formação de "capital humano" - formação de força de trabalho com mínima qualificação para a operacionalização dos novos pacotes de tecnologia a serem invertidos na agricultura. Na ocasião, várias políticas educacionais são realizadas para ajustar a educação às demandas dessa nova fase capitalista.

Dessa maneira, a educação foi sendo negada, historicamente, aos camponeses. Quando ofertada, buscava legitimar e consolidar os interesses das elites oligárquicas; depois, servir aos interesses do grande capital, nunca sendo pensada com os camponeses, mas sempre "moldada" para se aplicar aos camponeses.

A educação rural nunca foi alvo de interesse dos governantes, ficando sempre relegada ao segundo ou terceiro plano, "apêndice" da educação urbana. Foi e é uma educação que se limita à transmissão dos conhecimentos já elaborados e levados aos alunos da zona rural com a mesma metodologia usada nas escolas da cidade (BAPTISTA, 2003, p. 20-21).

No segundo momento deste trabalho, elaboramos uma análise da realidade da educação rural a partir das políticas do Estado implementadas sob a influência e os interesses das agências mediadoras do capital, tendo no Banco Mundial sua expressão máxima. Assim, iniciamos pela sistematização de diferentes dados (IBGE, 2009; INEP, 2007) que indicam a difícil situação educacional das populações do campo nas últimas décadas: o analfabetismo ainda reinante, o que se pode afirmar também pela baixa escolaridade média da população do campo; as péssimas condições de formação e valorização dos professores; dificuldade de acesso ao ensino médio por parte dos jovens do campo, ocasionado pelo sistemático fechamento de escolas do campo. 
Assim, torna-se inegável, a partir de 1990, o interesse cada vez maior do capital imperialista pelas políticas de educação: elaboração, financiamento e controle das políticas educacionais, diretamente realizados pelas suas agências ditas "multilaterais", a exemplo do Banco Mundial (BM) (SOUZA, 2014). Essas políticas de educação se justificam, por exemplo, nas assertivas do próprio BM (1990, p.2), ao expor que "as novas tecnologias e os novos métodos de produção dependem de uma força de trabalho bem qualificada e intelectualmente flexível". Assim, o objetivo de tais políticas "é o aumento do nível de educação e a capacitação da mão de obra" (BANCO MUNDIAL, 1990, p. 1, tradução nossa) para atender às demandas do capital por força de trabalho. No Brasil, essas demandas recaem, sobretudo, no setor do "agronegócio".

Setor esse que significa uma nova roupagem da agricultura capitalista, propagada como moderna e produtiva. "Agronegócio" é uma palavra relativamente nova, porém tem origem no sistema de plantation norte-americano, referindo-se ao modelo agropecuário capitalista, baseado em mecanização e commodities, chamados pelos capitalistas de "agronegócio". Corroborando Fabrini e Roos (2014, p.8), compreendemos que"o agronegócio é uma 'nova' face da agricultura capitalista que esconde o 'velho' caráter especulativo da agricultura capitalista (rentismo) e a superexploração da força de trabalho [...]". Esse setor se divide em três partes:

1) Negócios agropecuários propriamente ditos. Envolvem a atividade dos produtores rurais [...] constituídos na forma de pessoas físicas ou jurídicas.

2) Negócios pré-produção. Envolvem os setores industriais e comerciais que constituem o conjunto de fornecedores do chamado consumo produtivo, como equipamentos para infraestrutura produtiva, máquinas, fertilizantes, agrotóxicos, sementes, insumos, etc.

3) Negócios agropecuários pós-produção. Envolvem a compra, transporte, beneficiamento e venda dos produtos agropecuários desde os primeiros intermediários até os consumidores finais. Entre eles destacam transportadoras, supermercados e distribuidoras de alimentos, indústrias atacadistas, têxteis, frigoríficos, abatedouros, etc. (PAULINO; ALMEIDA, 2010, p.75).

Nesse contexto, observamos que os documentos que regem a legislação e as diretrizes da educação nacional, erigidos a partir da Constituição de 1988, fundem-se nas prerrogativas e nos interesses do referido sistema do capital, a partir das orientações e influências do BM. 
Nas contradições desse sistema, avançava-se, radicalmente, a luta pela terra no país na década de 1990, quando os movimentos sociais, vinculados à Via Campesina, engajam-se na luta pela educação, tornando evidente a questão agrária e a necessidade da reforma agrária. Inicia-se, nesse contexto, a formulação dos "novos paradigmas" de educação para o campo, que rompem com uma educação pensada para os camponeses para uma proposta de educação com os camponeses (CALDART, 2004; FERNANDES; MOLINA, 2004). Essa proposta foi centrada nos princípios da pedagogia do Movimento dos Trabalhadores Rurais Sem Terra (MST) (CALDART, 2000; MST, 1999).

Esboçamos ainda, mesmo que brevemente, no último tópico deste texto, o delineamento de uma pesquisa em curso, que estamos desenvolvendo para o mestrado em Educação. A referida pesquisa centra-se em elucidar quais os projetos alternativos de educação estão sendo construídos em uma área de assentamento da reforma agrária, na região do Sertão do Vale do São Francisco. E, a partir de então, identificar qual paradigma de educação existente, a partir da análise nas práticas educativas de educação do/no campo, em duas escolas que atendem a diversos assentamentos da referida região.

No entanto, este trabalho tem como caminho metodológico a análise do papel das políticas de educação criadas pelo capital para o Brasil, a partir da realidade da educação oferecida no campo e as perspectivas do paradigma da educação do campo. O estudo resulta das discussões e contribuições da disciplina Educação Popular e Movimentos Sociais e das revisões bibliográficas que estamos realizando para a pesquisa de mestrado em Educação. Além destas, utilizamos de alguns dados de fontes primárias, em importantes documentos (IBGE, INEP, INCRA, Banco Mundial, MST, etc.) e na legislação brasileira de educação.

\section{PANORAMA HISTÓRICO-DIALÉTICO DA EDUCAÇÃO NO CONTEXTO DA QUESTÃO AGRÁRIA BRASILEIRA}

As origens da base educacional oferecida no campo, a partir da chamada "educação rural", estão ligadas à Proclamação da República (1889). A instituição desse tipo de educação vinculada ao ideário republicanista, ideário esse baseado na burguesia europeia, pretendia "modernizar" a sociedade brasileira a partir da universalização da educação, tendo por base a"pedagogia da essência" (princípios da igualdade e da cidadania). Para tanto, o governo "[...] forçou os fazendeiros a abrirem escolas em suas fazendas" (SOUZA, 2014, p.100). Uma educação nas mãos dos coronéis, na base do pensamento latifundista, "[...] do assistencialismo, do controle político sobre a terra e as pessoas que nela vivem" (FERNANDES, 2004, p.37). 
A burguesia e sua nova ordem capitalista, ao passo da sua consolidação no poder, passam a adotar uma visão diferente daquela de "igualdade" entre os homens e adota a "pedagogia da existência": existem "diferenças" entre os homens. Essa prerrogativa indicava que"os homens não são essencialmente iguais: [...] há aqueles que têm mais capacidade e aqueles que têm menos capacidade [...]"(SAVIANI apud SOUZA, 2014, p.100). Assim, no Brasil, os camponeses eram os "diferentes", os atrasados, os ignorantes e eram considerados entrave para o "progresso" e a civilização. Alguns qualificativos pejorativos foram sendo atribuídos aos camponeses, como se observa no personagem Jeca Tatu, de Monteiro Lobato, que foi "[...] descrito pelo autor como um parasita da terra, preguiçoso e incapaz de evolução" (GARCIA, 2006, p.26, destaque do autor).

A partir de então, até a década de 1960, surgiram movimentos educacionais cujo objetivo era conter a migração dos camponeses para as cidades e a realizar a "fixação" (manutenção) dos camponeses no campo. Assim, surgia já nos anos de 1930, sob a influência norte-americana, a propagação do ideário da "Escola Nova", em crítica à educação existente e como nova proposta educacional, pautada nos ideários do liberalismo burguês de universalização, de maneira pública, obrigatória e laica'.

Conforme Souza (2014), essas "aspirações" eram formuladas pela influência hegemônica do imperialismo norte-americano, que necessitava lançar sua base ideológica. "Ao final da Primeira República, já havia conseguido sufocar a Pedagogia socialista e a Pedagogia libertária (anarquista), que tinham forte experiência no meio operário e foram duramente reprimidas pelo governo Vargas" (SOUZA, 2014, p. 106). Assim, o ideário da "Escola Nova" cumpriu seu papel reacionário e conservador, fornecendo importantes elementos na Era Vargas para a propagação dos valores nacionalistas e para a formação de uma mão de obra "especializada" para atender aos interesses do nascente capital industrial.

Com o objetivo de formar força de trabalho (trabalho técnicomanual) minimamente especializada para o mercado do capital (surgido com a industrialização), foram criadas na década de 1940 instituições como o Serviço Nacional de Aprendizagem Industrial (SENAI) e o Serviço Nacional de Aprendizagem Comercial (SENAC) (ROMANELLI, 1996), perspectiva essa que não se alterou a partir de então: a educação brasileira incorporaria a matriz curricular urbanizada e industrializada, e os organismos do grande capital norte-americano já começariam a se interessar pelas políticas de educação para o campo. Era necessário reter as lutas e organizações camponesas ${ }^{2}$. Assim, celebrar-se-iam diversos acordos entre o governo brasileiro e as agências norte-americanas para a educação no campo $^{3}$ (MEDONÇA, 2007). 
Em 1947, criou-se a Comissão Brasileiro-Americana de Educação das Populações Rurais (CBAR), submetida ao Ministério da Agricultura. Esse órgão, segundo Mendonça (2007), implantou ações no Norte e no Nordeste a partir dos "clubes agrícolas", ordenados junto às escolas primárias e na construção de centros de treinamento. Esse tipo de educação negava os conflitos no campo e agia para contê-los, ao mesmo tempo em que forjava uma identidade camponesa que fosse subalterna aos anseios das classes dominantes. Conforme Souza (2014, p.110), "eram escolas sobre as quais o imperialismo financiador e gestor tinha total controle".

A partir dos anos de 1950, firmaram-se os tratados de cooperação técnica entre Brasil e EUA, de que derivaram a Campanha Nacional de Educação Rural (CNER) e o Escritório Técnico de Agricultura Brasil-Estados Unidos (ETA). A CNER objetivava: a preparação de professores leigos; a "capacitação" dos filhos de camponeses para certas atividades agrícolas, e mesmo uma educação sanitária e de higiene, que prevenisse doenças e a própria mortalidade infantil. Já o ETA elaborou programas educacionais para oferecer assistência técnica aos camponeses, na conhecida forma (até os dias de hoje) de extensão rural ${ }^{4}$. Conforme Souza (2014, p.111), as ações desses programas pautavam-se numa educação para a submissão do campo brasileiro aos ditames e "[...] interesses do grande capital que se instalava na agricultura e oferecer alternativas à população camponesa, neutralizando-a e afastando-a das organizações de luta como as Ligas Camponesas, que proliferavam".

Dessa maneira, o objetivo da educação no campo era "fixar" e manter os camponeses na terra e, ao mesmo tempo, conter o aumento das lutas e organizações camponesas. A partir desse momento, haveria uma inversão de objetivos, que seria agora de retirar (expropriar) os camponeses de suas bases fundiárias para a implantação dos projetos agrícolas do grande capital, a partir da chamada "modernização agrícola". Esse processo foi propagado, na época, como política de expansão do capitalismo no campo, no qual a educação passaria a exercer papel fundamental.

A implantação do regime da ditadura militar foi a base decisiva para a referida expansão. Tão logo, dentro do plano de "recuperação econômica", os militares foram orientados, pelas agências norte-americanas, a adotar a educação como fator de "desenvolvimento", a partir de sua adequação ao modelo de expansão capitalista em curso. Assim, estabeleceram-se diversos “[...] convênios entre MEC [Ministério da Educação] e seus órgãos e a Agency for international development (AID) - para assistência técnica e cooperação financeira dessa Agência à organização do sistema educacional brasileiro. Este é, então, o período dos chamados 'Acordos MEC-USAID'"' (ROMANELLI, 1996, p. 
196). Nesse contexto, transcorria a"modernização da agricultura" e acreditava-se no fim do campesinato, com o estímulo aos camponeses para sair de suas bases fundiárias para as cidades. Até a década de 1970, os próprios latifundiários e empresários gerenciaram a educação no campo, conforme a Constituição dos militares de 1967:"As empresas comerciais, industriais e agrícolas são obrigadas a manter, pela forma que a lei estabelecer, o ensino primário gratuito de seus empregados e dos filhos destes" (BRASIL, 1967, art. 170).

Na realidade de exploração e expropriação sofridas, os camponeses buscavam alternativas como as oferecidas pelos movimentos populares, a exemplo dos Centros Populares de Cultura e do Movimento de Educação de Base, etc. Para contrapor tais iniciativas populares, os militares criaram dispositivos educacionais, tais como o Movimento Brasileiro de Alfabetização (MOBRAL) $)^{5}$ e, para o campo, o Programa Educação Rural (EDURURAL) ${ }^{6}$, também financiado pelo grande capital a partir da gerência do Banco Mundial. Segundo Souza (2014, p. 114), "este programa foi implantado no Nordeste. Assim como o Mobral, se configurou como instrumento ideológico do regime militar".

Segundo as formulações da autora, até a década de 1980, a educação presente no campo resumia-se, em geral, às escolas multisseriadas de nível fundamental I ( $1^{\circ}$ a $4^{\circ}$ séries). O nível fundamental II $\left(5^{\circ}\right.$ a $8^{\circ}$ séries) praticamente era inexistente. Com a nova política de esvaziamento do campo (de expropriação das terras camponesas), para dar espaço aos projetos da "modernização agrícola", as "escolinhas" multisseriadas foram sendo fechadas, e os estudantes do campo tiveram de se deslocar para escolas concentradas a longas distâncias.

A partir da década de 1990 em diante, o referido quadro educacional não se alteraria, mas, ao contrário, observa-se o aprofundamento de uma catástrofe educacional causada, sobretudo, pelas novas investidas do Estado nas políticas de educação, em consonância com os interesses do sistema do capital.

\section{A REALIDADE DA EDUCAÇÃO RURAL NAS INVESTIDAS DO ESTADO E O PARADIGMA DA EDUCAÇÃO DO CAMPO}

O processo educacional brasileiro no campo sempre buscou alcançar uma civilidade desejada, a "[...] transmitir um quadro de valores que legitima os interesses dominantes [...] através de uma dominação estrutural e uma subordinação hierárquica e implacavelmente impostas" (MÉSZÁROS, 2008, p. 35, destaque do autor). Dominação do capital sobre os trabalhadores, os camponeses, os indígenas, os quilombolas e que continua a ocorrer, também, com base no processo educacional, a partir das políticas de educação impostas pelas políticas do Banco Mundial (SOUZA, 2014). 
O que se observa é a continuidade de uma catástrofe educacional, no que se refere às últimas décadas, a partir do ano de 1990, sendo reinante ainda o analfabetismo: mais de $80 \%$ da população do campo é analfabeta ou não concluiu o ensino fundamental, sendo que $39 \%$ são analfabetas e $43 \%$ tem o ensino fundamental incompleto. $\mathrm{O}$ analfabetismo chega a $45,7 \%$ entre as mulheres e $38,1 \%$ entre os homens (IBGE, 2009). Verifica-se também que "[...] apenas $24 \%$ dos professores das séries iniciais do Ensino Fundamental que dão aula em zonas rurais no país têm curso superior. Eles chegam a ganhar até $60 \%$ menos que os docentes da zona urbana" (SOUZA, 2012, p. 165).

No ano de 2007, o Instituto Nacional de Estudos e Pesquisas Educacionais Anísio Teixeira (INEP) publicou uma pesquisa sobre o"Panorama da educação no campo". Alguns dos dados nos chamam a atenção: pouco mais de um quinto dos jovens da área rural, na faixa etária de 15 a 17 anos, está frequentando o ensino médio. Na região Nordeste, apenas $11,6 \%$ dessa faixa etária frequenta o ensino médio. Outro dado aponta que"a escolaridade média da população com 15 anos ou mais que vive na zona rural (4 anos) corresponde a quase metade da estimada para a população urbana (7,3 anos) [...]" (INEP, 2007, p. 14.).

A referida pesquisa, ainda, revela que, "dos 1.992.224 alunos residentes na zona rural atendidos pelo transporte escolar público, 62,4\% tiveram como destino uma escola urbana, sugerindo a carência de escolas rurais que oferecem ensino de $5^{\mathrm{a}}$ a $8^{\mathrm{a}}$ série" (INEP, 2007, p.37). Essa realidade não pode ser tratada como uma mera "carência de escolas rurais", como se elas nunca tivessem existido. O que não as faz existir, em muitos espaços, é o contínuo e progressivo fechamento de escolas do campo, crime este que foi analisado por pesquisadores da educação do campo, ao publicarem, em agosto de 2015, um artigo no qual Taffarel e Munarim $(2015$, p.46) retratam que, entre 2005 a 2015, "o número de escolas do campo brasileiras fechadas é enorme. As escolas foram reduzidas em 31,46\%, ou seja, 32.512 unidades foram fechadas". Segundo os autores, somente no ano de 2014, mais de 4 mil escolas foram fechadas, "quase absolutamente todas no campo" (TAFFAREL; MUNARIM, 2015, p.47). Reflexo da política de esvaziamento do campo, integrada à estratégia expansionista do capital.

Diante da referida realidade, observa-se o interesse maior do sistema do capital pela educação a partir dos anos de $1990^{7}$, tendo em vista a elaboração, o financiamento e o controle das políticas educacionais diretamente pelas agências "multilaterais" do grande capital, a exemplo do Banco Mundial (SOUZA, 2014). No ínterim das políticas de educação definidas pelo Banco Mundial, "as novas tecnologias e os novos métodos de produção 
dependem de uma força de trabalho bem qualificada e intelectualmente flexível" (BANCO MUNDIAL, 1990, p. 2, tradução nossa). Assim, o maior desafio educacional dos países de Terceiro Mundo "é o aumento do nível de educação e a capacitação da mão de obra" (BANCO MUNDIAL, 1990, p. 1, tradução nossa). Uma educação, portanto, que defina um quadro de sujeitos minimamente qualificados, passivos e operantes da grande engrenagem do sistema capitalista.

Em um dos documentos básicos do Banco Mundial, em que dá partida à gestação das políticas de educação para os países "subdesenvolvidos", a partir da Conferência Mundial sobre Educação para Todos (1990), observase a objetiva propagação de uma ideologia da "equidade" no acesso de todos à educação, porém, que propicie a adaptação dos camponeses e dos trabalhadores às novas tecnologias e à dinâmica de produção agrícola do grande capital:

Os conhecimentos de aritmética elementar ajudam aos agricultores a estimar os rendimentos de atividades anteriores e os riscos de atividades futuras, em tanto que o saber ler e escrever Ihes ajuda a aplicar apropriadamente a tecnologia agrícola moderna (por exemplo, os produtos químicos agrícolas, os fertilizantes artificiais e as novas variedades de sementes) para manter registros (BANCO MUNDIAL, 1990, p. 4, tradução nossa).

Assim, a educação necessária é aquela que forme uma base de capital humano. A teoria do "capital humano" foi incorporada à educação no Brasil na década de 1960, nas reformas de ensino realizadas para adequar a educação aos interesses econômico-sociais que acompanhavam, desde aquele momento, a "modernização agrícola" e industrial do país. A formação de capital humano resulta da demanda de exploração da força de trabalho pelo capital, minimamente qualificada para atender às novas técnicas do sistema produtivo.

A capacidade de um país para aplicar a tecnologia moderna à produção agrícola e industrial depende em grande medida da qualidade de seu capital humano. [...] A quantidade de adultos dos países em desenvolvimento com nível de instrução necessário para produzir, adquirir e aplicar as tecnologias modernas à produção agrícola-industrial é perigosamente baixa ${ }^{8}$ (BANCO MUNDIAL, 1990, p. 12, tradução e grifo nosso).

Como se vê, a política de esvaziamento do campo, de expropriação dos camponeses de suas bases fundiárias, é atrelada à educação e ao processo 
educativo de maneira geral, a partir da teoria de formação de "capital humano". Ideologicamente, os discursos são disseminados internamente, e as reformas educacionais são realizadas para ajustar a educação às demandas dessa nova fase capitalista. Conforme Frigotto (2006, p. 40), "a educação, então, é o principal capital humano enquanto concebida como produtora de capacidade de trabalho, potenciadora do fator trabalho. Nesse sentido, é um investimento como qualquer outro". Torna-se necessário formar trabalhadores com certas "habilidades e competências", conforme as exigências do sistema econômico. No campo, não se almejam analfabetos, mas um "nível de instrução" mínimo para os trabalhadores e camponeses, a fim de que se habilitem às tecnologias de produção agrícola-industrial do capital.

Desse modo, com a propagação da teoria do "capital humano", há outras implicações e sérias consequências para a sociedade. Isso porque, conforme Frigotto (2006. p.), do ponto de vista ideológico, a referida teoria procura naturalizar "[...] o conflito de classes, o antagonismo capital-trabalho pode ser superado mediante um processo meritocrático - pelo trabalho, especialmente pelo trabalho potenciado com educação, treinamento, etc". Assim, a dominação, as mazelas sociais, os altos níveis de exploração do trabalho não são responsabilidades do capital, existem pela falta de"recursos humanos" qualificados.

As políticas educacionais vão sendo elaboradas a partir destes preceitos (equidade, capital humano, competências e habilidades, individualismo, etc.) das agências multilaterais e dos teóricos do capitalismo. Dessa maneira, de acordo com Souza (2014), praticamente toda política educacional brasileira é produto da intervenção e da influência do Banco Mundial:

A LDB, o PNE, os Parâmetros Curriculares Nacionais, as Diretrizes Curriculares para os cursos de graduação, a tão propagada "gestão democrática", o orçamento participativo, a formação continuada, o FUNDEF, o FUNDEB, a Universidade Aberta do Brasil, os programas assistenciais como Bolsa Família, o PETI - Programa de Erradicação do Trabalho Infantil, etc. (SOUZA, 2014, p. 127).

O capital, por meio do Banco Mundial e de suas demais agências "multilaterais", intervém na educação por meio das políticas educacionais e do financiamento de programas e projetos educacionais que fazem parte da reestruturação do capitalismo. Nesse sentido, qual o lugar da educação do campo na legislação educacional brasileira? De que maneira a legislação e as políticas educacionais passaram a abordar a educação do campo, a partir da década de 1990 ? E, por fim, quais as alternativas encontradas pelos 
trabalhadores para a construção de um projeto popular de educação do campo?

Para responder a tais indagações, faremos uma breve análise da legislação educacional brasileira, erigida a partir da década de 1990, e sua relação com as referidas políticas do Banco Mundial, assim como apresentaremos o paradigma da educação do campo, na perspectiva de uma educação popular.

Com a chamada "redemocratização" do país, elaborou-se a atual Carta Constituinte em 1988 e, a partir dela, uma série de documentos foram construídos em razão das reformas educacionais implementadas, os quais destacamos: a nova Lei de Diretrizes e Bases da Educação Nacional (Lei no. 9.394/96) (BRASIL, 1996); o Plano Nacional de Educação (PNE - Lei 10.172/2001) (BRASIL, 2001), e os próprios Parâmetros Curriculares Nacionais (PCNs) (BRASIL, 1997). Assim, por esses documentos-base da educação nacional, observaremos o não lugar ocupado pela educação do campo, a partir de tais reformas educacionais.

A Lei de Diretrizes e Bases da Educação Nacional está alicerçada nas políticas do Banco Mundial, retratadas mais acima, para a educação, por meio dos princípios do neoliberalismo. Segundo Cunha (2013), por meio de um neotecnicismo pedagógico, a ideia de desenvolver "competências"' revelava uma articulação de maior dependência entre os sistemas educativos e as exigências do mundo produtivo [...]". Já "a função docente materializa-se pela ação instrumental de favorecer o alcance das competências por parte de seus alunos" (CUNHA, 2013, p. 8).

No que tange à educação do campo, a LDB representou a continuidade do tipo de educação (rural) e excludente já existente. $\mathrm{O}$ art. 28 da referida lei assegura apenas que "[...] os sistemas de ensino promoverão as adaptações necessárias à sua adequação, às peculiaridades da vida rural e de cada região" (BRASIL, 1996, p.10, destaque nosso), Ou seja, conforme Souza (2014, p.129), "propõe um mero ajuste da educação existente para as escolas do campo". Dessa maneira, a LDB, mesmo garantindo o direito à educação das populações camponesas, não garantiu a perspectiva de uma educação popular e de massas, cuja construção partisse das necessidades dos próprios sujeitos do campo. Pelo contrário, ocorreu a municipalização do ensino fundamental e as escolas do campo foram, paulatinamente, sendo fechadas. Para Souza (2014, p. 129), esta "é a estratégia de desocupação do campo sendo executada". O que ocorre, também, por vias do processo educacional.

O Plano Nacional de Educação (PNE), por sua vez, veio legitimar a referida "desocupação" do campo (nas expropriações camponesas), quando 
institui a política de fechamento das escolas multisseriadas ${ }^{9}$, situadas no seio das comunidades camponesas, e a institucionalização da política de transporte escolar para levar os alunos às escolas centralizadas. Para atender aos interesses do capital por força de trabalho, como enfatizado no documento do Banco Mundial, o PNE propõe as escolas técnicas de formação profissional específica e permanente para a população do campo, "[...] levando em conta seu nível de escolarização e as peculiaridades da atividade agrícola na região" (BRASIL, 2001, p. 50), "peculiaridades" estas baseadas em atender à demanda do agronegócio.

Os Parâmetros Curriculares Nacionais (PCNs), elaborados pela orientação das políticas do Banco Mundial, marcam o retorno ao antigo discurso das "diferenças" e ao antigo ideário da "igualdade", para mascarar as desigualdades sociais e as contradições de classes. Segundo os PCNs, "se existem diferenças socioculturais marcantes, que determinam diferentes necessidades de aprendizagem, existe também aquilo que é comum a todos, [...] o direito de aprender e esse direito deve ser garantido pelo Estado" (BRASIL, 1997, p. 28). Da mesma forma que a LDB, os parâmetros advogam que os temas "[...] exigem adaptações para que possam corresponder às reais necessidades de cada região ou mesmo de cada escola" (BRASIL, 1997, p. 45, destaque nosso). Assim, justificam e propõem-se as "adaptações" de um currículo centralizado para atender às necessidades educacionais dos camponeses.

Nesse contexto em que a legislação brasileira de educação, pósConstituição de 1988, continuou a tratar a educação no campo pelas mesmas condicionantes anteriores da "educação rural" e que a territorialização do capital no campo aumenta, paralelamente eclode a luta por terra e por uma educação como parte de um programa agrário. A partir de 1990, tem início a formulação dos "novos paradigmas" (CALDART, 2000; FERNANDES; MOLINA, 2004) para a educação do campo, centrados nos princípios da proposta pedagógica ${ }^{10}$ do Movimento dos Trabalhadores Rurais Sem-Terra (MST) (MST, 1999). Para tanto, conforme Souza (2014, p.136), "a discussão sobre educação do campo ganhou o País e alguns avanços foram alcançados, frutos da articulação entre os movimentos e os órgãos responsáveis por oferecer educação aos camponeses".

Assim, a realização do I Encontro Nacional de Educadores da Reforma Agrária (I ENERA) ${ }^{11}$, em 1997, fortaleceu as discussões sobre o termo educação do campo. Fernandes (2004, p.38) elucida que, a partir dessas discussões, "[...] começamos a cunhar o conceito de Educação do Campo", sobretudo, pela criação do "Movimento por uma Educação Básica do Campo", envolvendo 
grupos organizados e pesquisadores. Segundo Caldart (2004, p. 10) esse foi "[...] o momento do batismo coletivo de um novo jeito de lutar e pensar a educação para o povo brasileiro que vive e trabalha no e do campo". Ainda, segundo a autora:

Educação do campo e não mais educação rural ou educação para o meio rural. A proposta é pensar a educação do campo como processo de construção de um projeto de educação dos trabalhadores do campo gestado desde o ponto de vista dos camponeses e da trajetória de lutas de suas organizações (CALDART, 2004, p.13).

A partir de então, vários eventos e seminários ocorreram para o fortalecimento do campo da educação do campo. A exemplo do Seminário Nacional por uma Educação do Campo: Políticas Públicas e Identidade Política e Pedagógica das Escolas do Campo", realizado em novembro de 2002 na Universidade de Brasília (UnB). Esse evento objetivou aprofundar a discussão sobre políticas públicas a serem direcionadas a partir das novas Diretrizes Operacionais para a Educação Básica nas Escolas do Campo, recém-aprovadas pelo Conselho Nacional de Educação (CNE) e consideradas uma grandiosa conquista para a educação do campo. As referidas Diretrizes, que integram as atuais Diretrizes Curriculares Nacionais da Educação Básica, assim definem os objetivos da educação do campo:

Art. $4^{\circ}$ - O projeto institucional das escolas do campo constituirá num espaço público de investigação e articulação de experiências e estudos direcionado para o mundo do trabalho e o desenvolvimento social, economicamente justo e ecologicamente sustentável (BRASIL, 2013, p. 282, grifo nosso).

Nesse sentido, ao observarmos que os seminários e conferências, que trataram das definições do campo da educação do campo e o papel do Estado nas políticas educacionais, foram realizados em parceria com instituições ligadas ao Banco Mundial e ao grande capital, como a Organização das Nações Unidas para a Educação, Ciência e Cultura (UNESCO) e o Fundo das Nações Unidas para a Infância (UNICEF), por exemplo, devemos indagar, perante as diretrizes acima apresentadas: não seriam estas meras "adaptações", por mais progressistas que possam nos parecer, chavões ideológicos e fissuras compensatórias para mascarar a dominação? Ao instituir uma educação direcionada para o "mundo do trabalho", tais diretrizes não apontam para as prerrogativas do Banco Mundial de formação de um capital humano capaz de aplicar as tecnologias modernas à produção agrícola-industrial? Tornase possível no capitalismo um desenvolvimento "economicamente justo" e "ecologicamente sustentável"? 
No ano de 2004, ocorreu a II Conferência Nacional de Educação do Campo, pautando tanto pela ampliação dos grupos, universidades e representantes governamentais envolvidos com a educação do campo quanto pelas novas concepções educacionais. Nessas novas concepções, destacamos a proposição de uma articulação para a defesa da educação do campo, na inserção dos filhos dos trabalhadores do campo nos três níveis da educação básica (infantil, fundamental e médio) e nas universidades públicas brasileiras, pois necessita-se no campo também de profissionais qualificados. Assim, o perfil de escolas para o campo devia ser o de uma educação com os sujeitos do campo e não aquela"pensada" para os sujeitos do campo (SOUZA, 2014; CALDART, 2004; FERNANDES; MOLINA, 2004).

No referido percurso de consolidação deste novo paradigma da “Educação do Campo" (FERNANDES; MOLINA 2004), vale ressaltar o I Encontro Nacional de Pesquisa em Educação do Campo, importante encontro ocorrido em Brasília no mês de setembro de 2005. Esse evento reuniu pesquisadores de várias universidades do país e gerou um grande e acirrado debate em torno de temas relacionados à pesquisa e ao próprio papel das universidades perante a população do campo, a partir daquele contexto da reforma universitária do governo Lula. Na avaliação de Souza (2014), na referida ocasião, a reforma universitária, que estava sendo colocada em discussão pelo governo Lula, executada pelo Banco Mundial, foi questionada por vários professores e pesquisadores, porém defendida pelos dirigentes e teóricos do MST, acendendo um conflituoso debate.

A despeito da referida reforma universitária, o professor Roberto Leher (2003) afirma que esta ocorreu na junção entre o Banco Mundial e o próprio governo de Lula da Silva, na intermediação do Observatório Internacional de Reformas Universitárias (ORUS), uma organização não governamental (ONG) dirigida pelo pensador francês Edgar Morin. A crítica, deste e de outros pesquisadores, residia na perspectiva do grande capital em colocar a educação superior em conexão com o mercado, a partir da formação de "capital humano", trabalhadores qualificados para a disposição de força de trabalho à demanda produtiva do sistema do capital.

Contudo, observa-se que as políticas educacionais do Estado estão em fusão com os interesses do sistema do capital, voltadas para o "mundo do trabalho", em que os estudantes ora são estimulados a deixar o campo, ora são absorvidos pelo discurso conformista de que só resta o trabalho precarizado nas grandes empresas do agronegócio, realidade com a qual se se defrontam muitos dos jovens campesinos e trabalhadores da região do Vale do São Francisco (ALMEIDA; AMORIM; PEREIRA, 2016; AMORIM, 2016). 
O PARADIGMA DE EDUCAÇÃO NO/DO CAMPO PREDOMINANTE NO SERTÃO DO VALE DO SÃo FRANCISCO - UM DELINEAMENTO DE PESQUISA

Tomando por referência o sertão pernambucano do Vale do São Francisco, região na qual pesquisamos, inquieta-nos conhecer qual o paradigma de educação no/do campo predominante e quais práticas educativas estão sendo desenvolvidas em duas escolas que atendem a diversas comunidades de assentamento de reforma agrária.

No entanto, apresentamos tão-somente um delineamento de pesquisa que estamos desenvolvendo para o mestrado em Educação, um projeto que está em sua fase inicial: componentes curriculares, revisão bibliográfica, etc. Assim, os elementos referentes à citada proposição de pesquisa estão intercalados pela importante experiência tida na disciplina Educação Popular e Movimentos Sociais e na própria revisão bibliográfica, sobre a qual discorremos anteriormente, e que compõem o quadro teóricometodológico da pesquisa.

Na região supracitada, a luta pela terra teve seu auge na década de 1990, com um grande movimento de ocupações em latifúndios (fazendas falidas da agricultura irrigada), encabeçadas pelo Movimento dos Trabalhadores Rurais Sem Terra (MST). Nessa época,"o processo de organização dos trabalhadores para ocupação dessas fazendas improdutivas não foi muito difícil, visto que existia um grande contingente de mão-de-obra que havia ficado ociosa com o fim dos grandes projetos de fruticultura" (BRASIL, 2011, p. 23). O documento refere-se às diversas fazendas frutícolas, estruturadas na região com base na política do Estado em expandir o capitalismo no campo (a "modernização agrícola), mas que vieram à falência nas crises do sistema do capital nos anos de 1990, passando à condição de latifúndios improdutivos e trazendo desemprego para milhares de trabalhadores. Essa massa que ficara "ociosa" engajou-se na luta pela terra, realizando uma série de ocupações.

As áreas dessas antigas fazendas, ocupadas pelos trabalhadores sem terra, foram transformadas, até o ano 2000, em assentamentos de reforma agrária, totalizando 43 comunidades, em uma "área de aproximadamente 50 mil ha [...]" (BRASIL, 2011, p. 24), sobretudo, no entorno dos municípios pernambucanos de Lagoa Grande e Santa Maria da Boa Vista (BRASIL, 2011). Tais comunidades de assentamento são atendidas por poucas escolas, destacando-se duas: a Escola Municipal Professor José Arnaldo da Silva e a Escola Municipal de Catalunha, redes municipais de Lagoa Grande e Santa Maria, respectivamente.

A Escola Professor José Arnaldo foi recém-inaugurada pelo município de Lagoa Grande (PE), no ano de 2016, construída por meio de parceria entre prefeitura e Fundo Nacional de Desenvolvimento da Educação e propagada 
como a primeira escola do campo no município com "padrão MEC". Ela foi centralizada para atender a várias dessas comunidades de assentamento do entorno e outras comunidades camponesas que tiveram suas escolas locais fechadas. Já a Escola Municipal de Catalunha, ao contrário, existente como "escola itinerante" (1996-98) desde a época do acampamento dos sem-terra, foi instituída como escola municipal e mantida sob a base da pedagogia do Movimento Sem Terra (CALDART, 2000). A referida escola já chegou a responder por $10 \%$ da matrícula total da educação infantil e do ensino fundamental do município de Santa Maria da Boa Vista (SILVA; HILÁRIO, 2011).

No desdobramento desse processo histórico de luta pelo acesso à terra, nos espaços de assentamentos aqui referidos, encontra-se, atualmente, uma acentuada contradição entre as comunidades oriundas dessa política de reforma agrária e as grandes fazendas de produção do agronegócio (ALMEIDA; AMORIM; PEREIRA, 2016). Nesse sentido, torna-se relevante conhecermos os impactos do processo educativo na realidade de vida desses sujeitos do campo, por isso nos propomos a investigar qual o paradigma de educação predominante em tais escolas e a possível existência de projetos educacionais alternativos. Preocupa-nos conhecer ainda como são tratados os temas da questão agrária e da luta pela terra nas práticas educativas e quais os efeitos do processo educativo formal na realidade de vida dos sujeitos do campo, pertencentes aos assentamentos de reforma agrária.

A elucidação dessas questões, a partir da investigação e da sistematização da análise, nos proporcionará conhecer as perspectivas do paradigma da educação do campo e as possíveis significações da "educação rural", a partir também das políticas educacionais locais, na região do Vale do São Francisco (sertão pernambucano). A pesquisa, que se torna relevante por inexistência de outra nesta perspectiva, trará um diagnóstico sobre os impactos e as significações do processo educativo oferecido nas comunidades camponesas supracitadas, para as próprias comunidades, movimentos sociais, pesquisadores e educadores da região.

\section{Algumas CONSIDERAÇÕES}

Na história educacional brasileira, historicamente, a educação no campo foi sempre caricaturada ou mesmo negada aos camponeses e trabalhadores rurais. Quando esteve presente, objetivava legitimar e consolidar os interesses das elites oligárquicas, num primeiro momento, e os interesses do grande capital, num segundo momento (1960 em diante).

A educação existente no campo centra-se em políticas do Estado, implementadas pela influência e para atender aos interesses do sistema do 
capital. Agentes como o Banco Mundial, a partir de 1990, passam a controlar as políticas educacionais: na elaboração, no financiamento e no controle das políticas educação, já que as novas tecnologias e os métodos de produção demandam força de trabalho qualificada e "intelectualmente flexível". As políticas de educação visam à formação e à capacitação de uma força de trabalho necessária à reprodução do capital e sua acumulação. É necessário, então, combater e erradicar o analfabetismo, justamente porque analfabetos não conseguem operar máquinas modernas nem dominar técnicas agrícolas.

Conforme avançava a luta pela terra no país, com a formação de acampamentos e assentamentos, os movimentos sociais se engajavam também em uma luta por educação, a educação do campo. Esta não mais pensada para os camponeses, mas materializada com os camponeses. Nessa perspectiva, esperamos que a pesquisa venha elucidar os projetos de educação do/no campo e suas implicações (positivas ou negativas) para os sujeitos do campo, a partir das políticas educacionais e das práticas educativas das escolas de assentamento da reforma agrária (sertão do Vale do São Francisco).

Por fim, há o entendimento de que tais questões não podem ser compreendidas de maneira reducionista à base do fenômeno educativo. Ao contrário, necessitam ser analisadas na base da estrutura econômico-social, no contexto da questão agrária e seus componentes: altíssima concentração de terras, crescente expansão do capital com base no agronegócio latifundiário, relações precárias e de altíssima exploração da força de trabalho, etc.

\section{THE EDUCATION IN THE CONTEXT OF THE BRAZILIAN AGRARIAN ISSUE AND THE STATE POLICIES TOWARDS THE EDUCATION IN/ OF RURAL AREAS}

AвSTRACT: This paper focuses on the education policies shaped by the State in Brazil, starting from the interests on the expansion of the capitalist system, particularly for rural areas which, contradictorily, contribute in creating an education that goes against the educational system in those rural areas. This education is shaped on the struggles of social movements in a moment that the agrarian issue is put in evidence on account of the lack of alternatives in the reinclusion of people expelled from their lands. In this respect, the aim of this paper is to analyze the State Policy towards the education in the rural areas in the context of the Brazilian agrarian issue. Accordingly, it is sought to unveil the educational policies implemented by the State, hosting the demands of 
the capital and the characterization of the meanings of an alternate project of Rural Education, emerged on the basis of the land-rights movements.

KEYWORDS: Agrarian Issue. Struggle for land. Educational policies. Rural areas education.

\section{LA EDUCACIÓN EN EL CONTEXTO DE LA CUESTIÓN AGRARIA BRASILEÑA Y LAS POLÍTICAS DEL ESTADO PARA LA EDUCACIÓN EN EL/DEL CAMPO}

RESUMEN: El artículo se centra en las políticas de educación desarrolladas por el gobierno brasileño, a partir de los intereses de expansión del sistema capitalista, especialmente, para el espacio rural que, al contrario, contribuye con la creación de una educación que camina contramano al sistema - la educación rural. Esta se construye en las luchas de los movimientos sociales, en el momento en que la cuestión agraria gana grande destaque por causa de la escasez de alternativas de re-inclusión de los que fueron expulsados de las tierras. En ese sentido, el objetivo de este artículo es analizar las políticas del Gobierno para la educación en/del campo en el contexto de cuestiones agrarias brasileñas. Por lo tanto, se buscó desvelar las políticas educativas implantadas por el Estado, en aceptación a las demandas del capital, y la caracterización de los significados del proyecto alternativo de educación rural, resultante de las bases de los movimientos de lucha por la tierra.

Palabras Clave: Cuestión agraria. Lucha por la tierra. Políticas educacionales. Educación del Campo.

\section{NOTAS}

1 Tendo como documento-base o Manifesto dos pioneiros da Educação Nova, de 1932.

2 Durante a República Velha e no período de Vargas, eclodiram várias lutas camponesas de grande significação: Canudos, Contestado, Caldeirão e Pau de Colher, etc., que se somaram aos levantes operário-camponeses (dirigidos pelo Partido Comunista), como a Coluna Prestes e o Levante de 1935.

3 A exemplo do acordo de 1945, entre o governo brasileiro e a Fundação Interamericana de Educação, para a relação com professores dos Estados Unidos, especializados em ensino profissional agrícola.

40 ETA firmou convênios e parcerias com dezenas de entidades ligadas às associações de crédito e de assistência rural, tanto públicas quanto privadas, a partir da ideologia do capital norte-americano de "comunidades de cooperação", "associativismo", etc., para atender aos interesses do grande capital norte-americano e decretar completa subserviência do Brasil aos EUA. O que se constata pelas próprias listagens de 
patrocinadores, tais como AID, ICA, Aliança para o Progresso, Fundação Rockfeller, Fundação Kellog, etc.

5 Movimento Brasileiro de Alfabetização (MOBRAL) - projeto do governo militar brasileiro criado pela Lei $n^{\circ}$ 5.379, de 15 de dezembro de 1967, propunha realizar a alfabetização funcional da população brasileira.

6 O programa EDURURAL (1980-1985) foi uma proposta pedagógica "adaptada ao meio" rural, especificamente da região Nordeste, criado pelo Decreto n 85.287 , de 23 de dezembro de 1980.

7 Há várias políticas educacionais impostas, a serem aplicadas nos países "subdesenvolvidos"(semicoloniais), para ajustar a educação aos interesses de exploração econômica do capital. Em março de 1990, ocorreu a Conferência Mundial sobre Educação para Todos, organizada por diversos organismos internacionais (UNESCO, UNICEF, PNUD, BID), ocasião em que se aprova a Declaração Mundial sobre Educação para Todos e, nela, as diretrizes internacionais para a universalização de um acesso mínimo de todos à educação, inclusive das populações rurais.

8 Texto original em espanhol.

9 Reforçada pelo discurso da má qualidade da educação nas escolas de tipo multisseriadas (unidocentes), também propagadas como "escolas isoladas", de difícil acesso para as políticas de educação, da merenda escolar e da avaliação educacional. No entanto, estas eram escolas que se situavam no seio das comunidades camponesas e possibilitavam a integração interna delas com seu modo de vida e produção.

10 Proposta constituída por princípios filosóficos e pedagógicos, integrados pela necessidade da luta pela terra e de territorialização do MST, juntando-se às experiências do movimento com educação popular, como exemplo da experiência das "escolas itinerantes" nos processos de ocupação (acampamentos).

11 Parceria entre a Universidade de Brasília (UnB), Fundo das Nações Unidas para a Infância (UNICEF), Organização das Nações Unidas para Educação, Ciência e Cultura (UNESCO) e a Conferência Nacional dos Bispos do Brasil (CNBB).

\section{REFERÊNCIAS}

AMORIM, F. C. L. As contradições da política de (contra)reforma agrária no Vale do São Francisco: o caso do "Projeto de Assentamento - PA Catalunha" (1988-1998). Temporalidades - Revista de História, v.8, n. 3, set./dez. 2016.

ALMEIDA, M. D.; AMORIM, F. C. L; PEREIRA, F. A política de reforma agrária no Vale do São Francisco: semifeudalidade e capitalismo burocrático no campo. Revista NERA, Presidente Prudente, a.19, n.33, p. 181-205, set.-dez. 2016

BRASIL. Constituição da República Federativa do Brasil de 1967. Presidência da República. Casa Civil: Subchefia para Assuntos Jurídicos. Brasília, 24. jan. 1967. 
. Lei no 9.394, de 20 de dezembro de 1996. Estabelece as diretrizes e bases da educação nacional. Presidência da República. Casa Civil: Subchefia para Assuntos Jurídicos. Brasília, 20 dez. 1996.

. Brasil. Secretaria de Educação Fundamental. Parâmetros curriculares nacionais: introdução aos parâmetros curriculares nacionais. Brasília: MEC/SEF, 1997.

. Lei n 010172, de 9 de janeiro de 2001. Aprova o Plano Nacional de Educação e dá outras providências. Presidência da República. Casa Civil: Subchefia para Assuntos Jurídicos. Brasília, 9 jan. 2001.

. Ministério de Desenvolvimento Agrário. Plano Territorial de Desenvolvimento Rural Sustentável do Sertão do São Francisco - Pernambuco. Brasília, DF, 2011.

. Diretrizes Curriculares Nacionais Gerais da Educação Básica. Ministério da Educação. Secretaria de Educação Básica. Diretoria de Currículos e Educação Integral. Brasília: MEC, SEB, DICEI, 2013.

BANCO MUNDIAL. El mejoramiento de la educación primaria en los países en desarrollo: examen de las opciones de política. In: CONFERÊNCIA DE EDUCAÇÃO PARA TODOS. Bangkok, mar. 1990.

BAPTISTA, F. M. C. Educação rural: das experiências à política pública. Brasília: NEAD, 2003.

CALDART, R. S. Pedagogia do Movimento Sem Terra: escola é mais que escola. 2 ed. Petrópolis: Vozes, 2000.

. Elementos para construção do projeto político e pedagógico da educação do campo. In: MOLINA, M. C.; JESUS, S. M. S. A. Contribuições para a construção de um projeto de educação do campo. Brasília: Articulação Nacional Por uma Educação do Campo, 2004, p. 13-52. (Coleção Por uma Educação do Campo, n.5).

CUNHA, M. I. O tema da formação de professores: trajetórias e tendências do campo na pesquisa e na ação, Educação e Pesquisa, São Paulo, 2013, p.1-17.

FABRINI, J. E.; ROOS, D. Conflitos territoriais entre o campesinato e o agronegócio latifundiário. São Paulo: Outras Expressões, 2014.

FERNANDES, B. M.; MOLINA, M. C. O campo da educação do campo. In: JESUS, S. M. S. A.; MOLINA, M.C. (Org.). Contribuições para um projeto de educação no campo. Brasília: Articulação Nacional por uma Educação do Campo, 2004. p.32-53.

FRIGOTTO, G. A produtividade da escola improdutiva: um (re)exame das relações entre educação e estrutura econômico-social e capitalista. 8. ed. São Paulo: Cortez, 2006.

GARCIA, E. M. S. A educação do homem do campo (1920-1940). 2006. 181 f. Dissertação (Mestrado em Educação) - Universidade São Francisco, Itatiba, 2006.

IBGE. INSTITUTO BRASILEIRO DE GEOGRAFIA E ESTATÍSTICA. Censo Agropecuário 2006: Brasil, Grandes Regiões e Unidades da Federação. Rio de Janeiro: IBGE, 2009. 
INEP. Instituto Nacional de Estudos e Pesquisas Educacionais Anísio Teixeira. Panorama da educação no campo. Brasília: INEP, 2007. 44 p.

LEHER, R. Reforma universitária do governo Lula: protagonismo do Banco Mundial e das lutas antineoliberais. Folha Dirigida, Rio de Janeiro, 16 dez. 2003.

MARTINS, J. S. O sujeito oculto: ordem e transgressão na reforma agrária. Porto Alegre: Editora da UFRGS, 2003. p. 25-159.

MENDONÇA, S. R. Conflitos intraestatais e políticas de educação agrícola no Brasil (1930-1950). Tempos Históricos, v. 10, p. 243-266, 2007.

MÉSZÁROS, I. A educação para além do capital. 2 ed. São Paulo: Boitempo, 2008.

MST. Movimento dos Trabalhadores Rurais Sem Terra. Como fazemos a escola de educação fundamental. São Paulo: MST, 1999. (Caderno de Educação, n.9).

PAULINO, E. T.; ALMEIDA, R. A. Terra e território: a questão camponesa no capitalismo. São Paulo: Expressão Popular, 2010.

ROMANELLI, O. O. História da educação no Brasil. Petrópolis, Vozes, 1996.

SAVIANI, D. O pensamento pedagógico brasileiro: da aspiração à ciência à ciência sob suspeição. Educação e Filosofia, Uberlândia, v.21, n.42, p.13-35, jul./dez. 2007.

SILVA, E. M. G.; HILÁRIO, E. Escola Municipal Catalunha: história e lições de uma escola de assentamento - Pernambuco. In: CAMINI, I.; LIMA, J. (Org.). Luta, história e movimento pedagógico da escola do MST na Bahia, no Pará e em Pernambuco. São Paulo: Expressão Popular, 2011.

SOUZA, M. M. Imperialismo e educação do campo. Araraquara: Cultura Acadêmica, 2014. Capitalismo burocrático e educação do campo na Amazônia ocidental: semicolonialismo e semifeudalidade. Revista EDUCAmazônia - Educação Sociedade e Meio Ambiente, Humaitá, a.5, v. IX, n.2, jp. 161-176, jul./dez. 2012.

TAFFAREL, C. Z.; MUNARIM, A. Pátria educadora e fechamento de escolas do campo: o crime continua. Revista Pedagógica, Chapecó, v. 17, n. 35, p. 41-51, maio/ago. 2015.

Franciel Coelho Luz de Amorim: Mestrando em Educação pelo Programa de Pós-Graduação em Formação de Professores e Práticas Interdisciplinares (PPGFPPI) pela Universidade de Pernambuco (UPE) - Campus Petrolina e graduado em História pela mesma instituição; Atualmente é professor da Educação Básica do Estado da Bahia. É integrante dos Grupos de Pesquisa: Sociedade e Natureza do Vale do São Francisco e História e Memória (UPE). Tem experiência em História com ênfase em História Social (História Agrária), Educação e Ensino. Atua nos seguintes temas: questão agrária, luta pela terra, movimentos sociais, políticas educacionais, educação no/do campo, ensino de História e interdisciplinaridade.

E-mail:francielupe@gmail.com 
Raimunda Áurea Dias de Sousa: Licenciada em Geografia pela UPE/ Campus Petrolina (1995). Mestre em Geografia na área de concentração Dinâmica dos Espaços Agrário e Regional pela Universidade Federal de Sergipe (2006). É doutora pela UFS na mesma área de concentração (2013), com doutorado-sanduíche na Universidade de Lisboa-Portugal (2012). Professora adjunta da UPE/Campus Petrolina e do Programa de Pós-graduação Formação de Professores e Práticas Interdisciplinares (PPGFPI), É integrante dos grupos de pesquisa Sociedade e Natureza do Vale do São Francisco pela UPE (Líder) e Estado, Capital, Trabalho e Políticas de Reordenamento Territoriais, vinculado ao NPGEO/UFS. Coordena o Centro de Estudos Agrários (CEA) e é editora-chefe do Boletim de Geografia do Vale do São Francisco. Tem experiência em Geografia com ênfase em Geografia Agrária e Ensino. Atuando nos seguintes temas; agro-hidronegócio, questão alimentar, Estado, trabalho, teoria agrária, território, modernização, movimentos sociais, desenvolvimento, irrigação, natureza, conflitos por água, ensino de Geografia e interdisciplinaridade.

E-mail:aurea.souza@upe.br 